\title{
Preparation and performance of amine-tartaric salt as potential clay swelling
}

\section{inhibitor}

\author{
Gang Chen ${ }^{1, *}$, Jiao Yan $^{1}$, Li Lili ${ }^{1}$, Jie Zhang $^{1}$, Xuefan Gu ${ }^{1}$, Hua Song ${ }^{2}$
}

\begin{abstract}
A series of small molecular clay swelling inhibitor was prepared with tartaric acid and amines, presented as amine-tartaric salts (ATS). The inhibitor was screened based on the linear expansion rate of bentonite. The results show that the inhibitor prepared with tartaric acid and triethylenetetramine with the mole ratio of 1:1 (named as ATS-4) is the best inhibitor of the hydration expansion and dispersion of bentonite. The inhibitive properties of ATS-4 were evaluated by various methods, including clay linear swelling tests, anti-swelling tests, mud ball immersing tests, mud-making inhibition experiments and particle distribution measurements etc. The results show that ATS-4 has superior performance to inhibit the hydration swelling and dispersion of clays by controlling the particle size of clay. On the other hand, the bentonite linear expansion rate in $0.5 \%$ ATS-4 aqueous solution is much lower than that of others, and the hydration expansion degree of the mud ball in ATS-4 aqueous solution is appreciably weaker than the control test, and it is compatible with the conventional additives in water-based drilling fluids. Then, the inhibition mechanism
\end{abstract}


1 of the amine-tartaric salt was well discussed based on thermogravimetric analysis

2 (TGA), scanning electron microscope (SEM), X-ray diffraction analysis (XRD),

3 single crystal X-ray diffraction and ion exchange tests.

4 Key words: amine-tartaric salt; hydration expansion; inhibitor; inhibition mechanism

\section{1. Introduction}

6 Shales are fine-grained sedimentary rocks that can be rich sources of petroleum and

7 natural gas. In recent years the exploration of shale oil and gas are increasing

8 dramatically. But there are many issues threating the drilling process such as, in the

9 drilling, the wellbore instability and formation damage resulting from rock strength

10 reduction, hydration expansion and dispersion of formation clay (Stamatakis et al,

11 1995; Retz et al, 1991). Generally, the main way to inhibit hydration expansion of

12 shale includes the following aspects: the inhibitors can be adsorbed on clay surface

13 through electrostatic interaction and forms a hydrophobic surface on the shale particle,

14 thereby inhibiting the penetration of water into the interlayers (Steiger and Leung,

15 1992; Wang et al, 2009). And the coupling force between the clay particles and

16 formation particles is increased through hydrogen bonds, anchoring effect etc., thus

17 making the interlayer space impermeable for water molecules (Qiu et al., 2011; Slade

18 et al., 2004). Consequently, a high level of shale inhibition can be achieved in drilling

19 operations, using various additives among which $\mathrm{KCl}$ is very common (van Oort et al.,

20 2003). But relatively high concentrations (up to $20 \mathrm{wt} \%$ ) are necessary to minimize

21 clay swelling, which is considered unfavorable to the receiving environment, limits 
1 inhibitor have been used widely, but polymers may be adsorbed on the surface of rock,

2 reducing reservoir permeability or even blocking the formation(Jiang et al, 2016;

3 Zhong et al, 2012). Moreover the high toxicity of cationic polymers limits their use

4 (Ni et al, 2016; Zhong et al, 2015). In order to alleviate the problems, a series of low

5 molecular weight ammonium salts exhibiting ideal inhibitive functions can make up

6 for these imperfection. They are not poisonous and hazardous, and their use in drilling

7 fluids could significantly reduce drilled cuttings disposal costs (Wang et al, 2007;

8 Zhang et al, 2007). To seek more alternative inhibitors in this work, the properties of

9 amine-carboxyl inhibitors are evaluated through experiments including linear

10 expansion, mud balls and bentonite inhibition tests etc. Also, the compatibility of

11 micromolecular ammonium salts with traditional drilling fluid additives were studied.

12 Furthermore, the inhibitive mechanism is discussed in detail.

\section{Materials and methods}

\subsection{Materials}

The drilling fluids were formulated using several additives. Diethylenetriamine, triethylenetetramine and tetraethylenepentamine were provided by Sinopharm Chemical Reagent Co. Ltd. Tartaric acid was purchased from Tianjin Kemiou Chemical Reagent Co. Ltd., China. Modified starch was supplied in domestic market. Bentonite was obtained from Changqing Bentonite Group Co. Ltd., China, and the chemical composition (wt.\%) is: $\mathrm{SiO}_{2} 60.54, \mathrm{Al}_{2} \mathrm{O}_{3} 23.93, \mathrm{FeO} 0.23, \mathrm{Fe}_{2} \mathrm{O}_{3} 4.29, \mathrm{MgO}$ 2.56, $\mathrm{CaO} 2.78, \mathrm{~K}_{2} \mathrm{O} 1.45$ and others 4.22.

\subsection{Preparation of ATS}


1 The series of amine-tartaric salts (ATS) was prepared using tartaric acid and organic

2 amines (diethylenetriamine, triethylenetetramine, tetraethylenepentamine) as raw

3 materials. A certain amount of acid and amine were dissolved in water in various

4 proportions (Chen et al, 2014), after stirred for $1 \mathrm{~h}$, the water in the mixture was

5 evaporated, and the resident was ATS. The final product, amine-tartaric salts, was

6 abbreviated as ATS in the following text. Scheme $\mathbf{1}$ is an example of the reaction of

$7 \quad$ tartaric acid and diethylenetriamine.

\section{$8 \quad$ 2.3. Swelling inhibition and mud ball immersing test}

9 The hydration swelling of montmorillonite is tested by a NP-01 shale expansion

10 instrument (Haitongda, Co., Ltd., Qingdao, China), in accordance with Chinese

11 Petroleum and Natural Gas Industry Standards SY/T6335-1997 and SY/T5971-1994.

12 Mud ball immersing test is as follows: montmorillonite $(10 \mathrm{~g})$ was used to make a

13 mud ball, and the mud ball was immersed in $80 \mathrm{~mL}$ tap water or other aqueous

14 solutions for $72 \mathrm{~h}$ (Chen et al, 2014; Zhang et al, 2014). Then the details of the

15 immersed mud balls were evaluated, including a check whether there are cracks or

16 dilapidation on the surface.

$17 \quad 2.4$ Bentonite inhibition test

$18400 \mathrm{~mL}$ of water containing certain amount of inhibitor was treated by $2 \%(\mathrm{~m} / \mathrm{m})$

19 bentonite. After stirred for $20 \mathrm{~min}$, the dispersion was hot rolled at $70{ }^{\circ} \mathrm{C}$ for $16 \mathrm{~h}$.

20 Then the rheological properties were measured after the samples were cooled to the

21 room temperature. After that the equivalent amount of drilling fluid bentonite was

22 added and the procedure was repeated until the dispersion became too viscous to be 
1 measured (Zhong et al, 2013).

22.5 Drilling fluid properties evaluation experiment

$34 \%(\mathrm{~m} / \mathrm{m})$ bentonite was dispersed in $350 \mathrm{~mL}$ of water containing a given amount of

4 inhibitor (Zhang et al, 2014). After stirring for $20 \mathrm{~min}$, aged for $16 \mathrm{~h}$ at room or high

5 temperature, the rheological properties and filtration of the fluid samples were

6 measured using a model ZNN-D6S viscometer (Haitongda, Co., Ltd., Qingdao,

7 China), including Apparent viscosity (AV), Plastic viscosity (PV), Yield point (YP),

8 Dynamic plastic ratio (YP/PV), API Filtration (FL) and Friction coefficient $(\mu)($ Chen,

9 2006). The apparent viscosity, plastic viscosity and yield point were calculated from

10300 and $600 \mathrm{rpm}$ readings using following formulas from petroleum and natural gas

11 industry standards for field testing of drilling fluids (API RP 13B-1-2009):

12 Apparent viscosity $(\mathrm{AV})=\phi_{600} / 2(\mathrm{mPa} \cdot \mathrm{s})$

13 Plastic viscosity $(\mathrm{PV})=\phi_{600}-\phi_{300}(\mathrm{mPa} \cdot \mathrm{s})$;

14 Yield point $(\mathrm{YP})=\left(\phi_{300}-\mathrm{PV}\right) / 2(\mathrm{~Pa})$.

$15 \quad 2.6$ Particle size distribution test

$164 \%(\mathrm{~m} / \mathrm{m})$ bentonite dispersion was prepared and prehydrated for $24 \mathrm{~h}$. Inhibitors with

17 certain concentrations were added into the dispersion and stirred for $20 \mathrm{~min}$, after

18 aged for $24 \mathrm{~h}$, the size distribution of the particles was measured by LS-13 320 laser

19 particle size analyzer based on the light scattering principle (Beckman Coulter, Inc.,

20 USA), using equipment operating procedure under the pump speed of $45 \%$.

212.7 TGA, SEM and XRD

22 After the bentonite was dispersed in inhibitor solutions for $24 \mathrm{~h}$, the bentonite was 
1 separated and dried at $105^{\circ} \mathrm{C}$ for thermogravimetric analysis (TGA) and scanning

2 electron microscopy(SEM). TGA experiments were performed on a TGA/DSC 1/1600

3 thermal analysis machine (METTLER TOLEDO, Inc, Switzerland) at a ramp of $10^{\circ} \mathrm{C}$

4 /min from $50^{\circ} \mathrm{C}$ to $400^{\circ} \mathrm{C}$ under a flow of nitrogen. The surface morphology of the

5 sample under study in the absence and presence of inhibitors was investigated using a

6 Digital Microscope Imaging scanning electron microscope (model SU6600, serial No.

7 HI-2102-0003) at accelerating voltage of $20.0 \mathrm{kV}$. Samples were attached on the top

8 of an aluminum stopper by means of carbon conductive adhesive tape. All

9 micrographs of the specimen were taken at 5009 times magnification. X-ray

10 diffraction analysis (XRD) analysis was performed by using an X'pert PRO MPD

11 diffractometer with $\mathrm{Cu}$ target at a generator voltage of $45 \mathrm{kV}$, current of $50 \mathrm{~mA}$.

12 Samples were measured scanning $2 \theta$

$13 \quad 3$ Results and discussion

$14 \quad 3.1$ Preparation and swelling inhibition

15 The series of amine-tartaric salts (ATS) was prepared using tartaric acid and organic

16 amines (diethylenetriamine, triethylenetetramine, tetraethylenepentamine) as raw

17 materials. As shown in Table 1, the linear swelling ratio of ATS to clay was affected

18 by the type of amine, mole ratio of the functional group and the mass fraction of

19 inhibitors, and the linear expansion rate of bentonite in ATS-4 solution is much lower

20 than that of others within $30 \mathrm{~min}$. So ATS-4 was selected to be studied in detail in

21 following works.

22 In order to investigate the influence of ATS-4 to the swelling inhibition of bentonite, 
1 the swelling rate in different concentration of ATS-4 solutions was recorded. As

2 shown in Fig.1, the swelling rate of bentonite with time at different concentrations of

3 ATS-4 was recorded. As can be seen, the clay swelling rate increases dramatically at

4 the initial $10 \mathrm{~min}$, followed by slow increase. Compared with blank, the bentonite

5 linear expansion rate in 5.0\% ATS-4 aqueous solution is much lower, but the

6 concentration is larger. Under the condition of lower concentration, the swelling rate

7 in $0.5 \%$ ATS-4 solution is lower than that of others, and its effect is similar to the one

8 observed when using $1.0 \% \mathrm{KCl}$ solution, indicating that $0.5 \%$ ATS-4 can restrain the

9 water affinity of the montmorillonite effectively, and $0.5 \%$ should be an economical

10 concentration.

113.2 Mud ball immersing test

12 The mud ball immersing tests provide a more intuitive way to describe the inhibition

13 property of ATS-4. The mud balls were immersed into water and $0.5 \%$ ATS-4

14 solution respectively. Fig. 2 shows a visual aspect of the mud balls after $72 \mathrm{~h}$ of

15 immersion. The mud ball immersed in water swells obviously, and surface is loose,

16 while the mud ball immersed in $0.5 \%$ ATS-4 solution swells slightly, and the surface

17 is smoother and cracked. It is clear that ATS-4 has a significantly strong clay-swelling

18 inhibition capability. The phenomena could be explained by a surface film on the clay

19 resulting from absorption of ATS-4, which blocks the water penetration into the clay

20 and prevent clay from hydrating swelling.

\subsection{Bentonite inhibition test}

22 The test was projected to simulate the relatively slow incorporation of yielding clays 
1 into a drilling fluid. This simulated process usually happens when drilling active clays

2 in the stratum. As shown in Fig.3, with the amount of bentonite concentration

3 increasing, yield point of drilling fluid keeps increasing. And yield point increased

4 sharply with the addition of bentonite in fresh water system due to the hydration and

5 dispersion of montmorillonite. Comparing to blank, the lower rheological profile of

$6 \quad 0.5 \%$ ATS-4 proves that it performs good inhibitive capacity.

73.4 Effect of ATS-4 on the rheological properties and filtration of drilling fluids

8 To evaluate the applicability in drilling fluid, the effects of ATS-4 on the rheological

9 performance of drilling fluids as measured in accordance with API RP 13B-1-2009

10 were shown in Table 2. As can be seen from Table 2, compared with the non-additive

11 control sample, addition of $0.1 \%$ ATS-4 exhibited little influence on the viscosity and

12 API filtration of drilling fluid, but the filtration rate increased dramatically as $0.5 \%$

13 ATS-4 was used. So $0.1 \%$ ATS-4 was used to study the compatibility with common

14 drilling fluid additives. $0.1 \%$ ATS-4 and modified starch can improve viscosity and

15 reduce filtration of drilling fluid at the room temperature effectively, but are

16 incompatible with PAM. Thus, ATS-4 exhibits an excellent compatibility with the

17 modified starch in water-based drilling fluids.

\subsection{Particle size distribution test}

19 To study the function in the water-based drilling fluid, the effect of ATS-4 on the

20 bentonite in water was investigated. Fig. 4 shows the particle size distribution of the

21 bentonite dispersions when these are treated in different ways. Compared to the

22 un-hydrated control sample, the average size of hydrated bentonite particles is 
1 reduced from $26.65 \mu \mathrm{m}$ to $7.64 \mu \mathrm{m}$. And it should be noticed that it is different when

2 ATS-4 was added before and after the hydration of bentonite. When ATS-4 was

3 added before the virgin bentonite was dispersed into water, after $16 \mathrm{~h}$, the average size

4 of clays changed slightly, and it is just a little smaller than that of virgin bentonite.

5 When $0.5 \%$ ATS-4 was added to the hydrated bentonite suspension, the partials grow

6 up and are much larger than those of the blank suspension possibly due to flocculation.

7 The results confirm that ATS-4 can inhibit the bentonite swelling and dispersing, and

8 can aggregate the hydrated bentonite.

$9 \quad 3.6$ Thermogravimetric analysis

10 Thermogravimetric analysis (TGA) measure a mass loss of the hybrids as a function

11 of temperature. The decomposition of organic-inorganic hybrids would take place in

12 four steps: water desorption, dehydration, decomposition of polyammonium and

13 dehydroxylation ( $\mathrm{Xi}$ et al, 2004). As shown in Fig. 5, several mass loss steps are

14 observed in the curves of bentonite immersed in tap water and ATS-4 solution. The

15 thermal degradation of the ATS-4 treated bentonites differs significantly from that of

16 the control bentonite between $50^{\circ} \mathrm{C}$ and $400^{\circ} \mathrm{C}$. The weight loss of bentonite treated

17 with tap water is $3.3 \%$ from $50^{\circ} \mathrm{C}$ to $225^{\circ} \mathrm{C}$, while the weight loss of ATS-4 modified

18 bentonite is no more than $1.5 \%$, and there was obvious mass loss step from $270^{\circ} \mathrm{C}$ to

$19320^{\circ} \mathrm{C}$ for A line, which may be due to polymer degradation. Obviously, it can be

20 concluded that ATS-4 can inhibit the water absorption of bentonite effectively.

\subsection{Scanning electron microscopy}

22 In order to evaluate the morphology of bentonite particles treated by different ways, 
1 scanning electron microscopy (SEM) was carried out. Fig.6 (A) shows SEM image of

2 the bentonite after immersed in 0.5\% ATS-4 solution. Fig.6 (B) shows the bentonite

3 after immersed in water, and Fig.6 (C) shows SEM image of the virgin bentonite

4 without any treatment. From the three photos, it is observed that after immersed in

5 water, the particles dispersed and changed to smaller particles. However, the particle

6 size of ATS-4 treated sample is similar with that of the virgin sample but much larger

7 than that of tap water treated sample. It is anticipated that, except for electrostatic

8 interaction, the hydrogen bonding between ammonium group, hydroxyl group and

9 siloxane of clay and modification of surface affinity toward water can further restrict the swelling and hydration of clay minerals (Qiu et al, 2011).

\subsection{X-ray diffraction analysis}

The interlayer spacing of water immersed bentonite and ATS-4 solution immersed bentonite was measured by XRD, as shown in Fig. 7. The scan for water immersed bentonite indicates an intense peak at $5.908^{\circ}$, and an intense peak at $6.105^{\circ}$ for $0.5 \%$ ATS-4 solution immersed bentonite. The interlayer spacing can be calculated using Bragg law, $2 \mathrm{~d} \sin \theta=\lambda(\lambda=0.154 \mathrm{~nm})$. The interlayer spacing of the water immersed bentonite is $1.494 \mathrm{~nm}$, while $0.5 \%$ ATS- 4 was used, the interlayer spacing decreased to $1.446 \mathrm{~nm}$, indicating the effect of ATS-4.

\subsection{Inhibition mechanism}

In order to study the inhibition mechanism of amine-tartaric salts to bentonite, the mud ball was immersed in 0.5\% ATS-4 solution for 5d, as show in Fig.8 (left), there are many crystals precipitated on the mud ball surface and at the bottom of the beaker. 
1 The crystals were picked out and analyzed. The structure of the crystal was confirmed

2 by single crystal X-ray diffraction, as shown in Fig.8 (right). All the geometric

3 parameters of the crystal are in the usual ranges, as shown in Table 4. It crystallizes in

4 orthohombic $P 2{ }_{1} 2{ }_{1} 2_{1}$ space group, and the unit cell dimensions is: $a=9.631(2) \AA$

$5 \mathrm{~b}=10.573(3) \AA \mathrm{c}=9.215(2) \AA$. In the crystal, each central $\mathrm{Ca}^{2+}$ cation was coordinated

6 with eight $\mathrm{O}$ atoms, among which four carboxyl $\mathrm{O}$ atoms and two hydroxl $\mathrm{O}$ atoms

7 come from the four tartaric anions, and two hydroxl $\mathrm{O}$ atoms come from two $\mathrm{H}_{2} \mathrm{O}$

8 molecules. The four tartaric anions behave two types of coordination with $\mathrm{Ca}^{2+}$ cation,

9 two tartaric anions coordinate with $\mathrm{Ca}^{2+}$ cation by one carboxyl $\mathrm{O}$ atom and one

10 hydroxl $\mathrm{O}$ atom, while the other two tartaric anions coordinate with $\mathrm{Ca}^{2+}$ cation by

11 only one carboxyl $\mathrm{O}$ atom.

Then, the bentonite powder was immersed and stirred in $0.5 \%$ ATS-4 solution, and the ion exchange was measured by EDTA method, as show in Fig.9. The result shows

14 that the concentration of $\mathrm{Ca}^{2+}$ in solution increases with time. So the inhibition 15 mechanism of ATS-4 to bentonite can be attributed to the ion exchange of ammonium 16 with the calcium ion in bentonite, and the exchanged ammonium in the layers of 17 bentonite can concatenate the layers by the electrostatic attraction and hydrogen bonds

18 between the ammonium and silicon hydroxyl groups. Besides, the exchanged 19 ammonium and the electrostatic adsorbed tartaric anion also can block the water 20 entering the interspaces of the layers, so as to inhibit the swelling of bentonite.

\section{4. Conclusions}

22 In this work, amine-tartaric salts were synthesized using tartaric acid and organic 
1 amines (diethylenetriamine, triethylenetetramine, tetraethylenepentamine). The

2 inhibitive properties of ATS-4 towards clays swelling were investigated using linear

3 expansion tests, mud ball immersing tests etc. The results indicate that ATS-4 shows

4 stronger inhibition to hydration and swelling of bentonite. The hydration expansion

5 degree of the mud ball in ATS-4 solution was significantly weaker than that of blank.

6 The compatibility tests indicate that ATS-4 could be compatible with the conventional

7 additives in water-based drilling fluids and that it can control the particle size of

8 bentonite. The inhibition mechanism of amine-tartaric salt to shale may be due to the

9 ion exchange, hydrogen bonding and modification of surface affinity toward water.

\section{Acknowledgment}

11 This work was financially supported by the grants from National Science Foundation 12 of China (Program No. 50874092) and Scientific Research Program Funded by

13 Shaanxi Provincial Education Department (Program No. 16JS094).

14 References

15 Chen, D.J., Chen, F., 2006. Oil and gas fields applied chemistry. Petroleum Industry 16 Press, Beijing.

17 Chen G., Cai D., Zhang J., 2014. Preparation and performance study of carboxylic acid amine salt type clay swelling inhibitor. Natural Gas and Oil 32, 68-72.

19 Chen G., Zhang J., Yang N.W., Ma Y.F., 2014. The evaluation of sodium 20 hydroxymethyl lignosulfonate as an ecofriendly drilling fluid additive, Petrol. $21 \quad$ Sci. Technol. 32, 1816-1823.

22 Jiang G.C., Qi Y.R., An Y.X., Huang X.B., Ren Y.J., 2016. Polyethyleneimine as shale 
inhibitor in drilling fluid, App. Clay Sci. 127-128, 70-77.

2 Ni W.J., Li Q., Chen G., Li L.L., Zhang J., Zhang L., Yan J., Cheng C., 2016. Preparation and application of a glucose graft copolyammonium as shale inhibitor, Russ. J. App. Chem. 89(8), 1354-1359.

Patel, A.D., Swaco, M.I., 2009. Design and development of quaternary amine compounds: shale inhibition with improved environmental profile, Paper SPE 121737, International Symposium on Oilfield Chemistry, pp. 20.

Qiu Z.S., Zhong H.Y., Huang W.A.. 2011. Properties and mechanism of a new polyamine shale inhibitor[J]. Acta Petrolei Sinica 32. 678-682.

Retz, R.H., Friedheim, J., Lee, L.J., Welch, O.O., 1991. An environmentally acceptable and field-practical, cationic polymer mud system. Paper SPE 23064 Prepared for Presentation at the Offshore Europe Conference Held in Aberdeen, 3-6 September.

Slade P.G., Gates W.P., 2004. The swelling of HDTMA smectites as influenced by their preparation and layer charges, App. Clay Sci. 25, 93-101.

Steiger, R.P., Leung, P.K., 1992. Qualitative determination of the mechanical properties of shales. Paper SPE 18024, SPE Drilling Engineering, vol. 7, no. 3, pp. 181.

van Oort, E., 2003. On the physical and chemical stability of shales. J. Petrol. Sci. Eng $38,213-235$.

Wang, J.H., Yan, J.N., Ding, T.W., 2007. Progresses in the researches on high performance water base muds. Drill. Fluid \& Complet. Fluid 1, 1-2. 
1 Wang W.B., Zhang J.P., Wang A.Q., 2009. Preparation and swelling properties of superabsorbent nanocomposites based on natural guar gum and organo-vermiculite, App. Clay Sci. 46, 21-26.

Xi, Y., Ding, Z., He, H., Frost, R.L., 2004. Structure of organoclays-an X-ray diffraction and thermogravimetric analysis study. J. Colloid Interface Sci. 277, $116-120$.

Zhang, J., Cai, D., Chen, G., 2014. Performance assessment of a polyamine swelling inhibitor for clays and shales. Nat. Gas Ind. 34, 85-90.

Zhang J., Chen G., Yang N.W., Wang Y.G., 2014. Preparation of nitration-oxidation lignosulfonate as an ecofriendly drilling fluid additive, Petrol. Sci. Technol. 32, $1661-1668$.

Zhang, K.Q., He, L., An, S.F., 2007. An introduction to the high performance water base muds abroad, Drill. Fluid \& Complet. Fluid 3, 1-3.

Zhong H.Y., Qiu Z.S. and Huang W.A., 2013. Bis(hexamethylene)triamine as potential shale inhibitor in water-based drilling fluid, J. Petrol. Eng. 6, 55-56.

Zhong H.Y., Qiu Z.S., Huang W.A., Cao J., 2012. Poly (oxypropylene)-amidoamine modified bentonite as potential shale inhibitor in water-based drilling fluids, App. Clay Sci. 67-68, 36-43.

Zhong H.Y., Qiu Z.S., Huang W.A., Sun D., Zhang D.M., Cao J., 2015. Synergistic stabilization of shale by a mixture of polyamidoamine dendrimers modified bentonite with various generations in water-based drilling fluid, App. Clay Sci. 114, 359-369. 
Table 1 Name and inhibitory activity of amine-tartaric salts

\begin{tabular}{ccccc}
\hline & Materials & Ratio & Name & Swelling ratio/\% \\
\hline \multirow{3}{*}{ diethylenetriamine } & $1: 1$ & ATS-1 & 69.44 \\
& & $1: 2$ & ATS-2 & 66.94 \\
\cline { 3 - 5 } tartaric & $1: 3$ & ATS-3 & 67.88 \\
acid & \multirow{2}{*}{ triethylenetetramine } & $1: 1$ & ATS-4 & 60.37 \\
& & $1: 2$ & ATS-5 & 63.46 \\
\cline { 2 - 5 } & & $1: 1$ & ATS-6 & 68.52 \\
& \multirow{2}{*}{ tetraethylenepentamine } & $1: 2$ & ATS-8 & 63.20 \\
& & $1: 3$ & ATS-9 & 60.47 \\
\hline
\end{tabular}


Table 2 The effects of ATS-4 to the rheological performance of drilling fluids as measured in accordance with API RP 13B-1-2009 at room temperature

\begin{tabular}{lcccccc}
\hline \multicolumn{1}{c}{ Additives } & $\begin{array}{c}A V \\
/ \mathrm{mPa} \bullet \mathrm{s}\end{array}$ & $\begin{array}{c}P V \\
/ \mathrm{mPa} \bullet \mathrm{s}\end{array}$ & $\begin{array}{c}Y P \\
/ \mathrm{Pa}\end{array}$ & $\begin{array}{c}Y P / P V \\
\mathrm{~Pa} / \mathrm{mPa} \bullet \mathrm{s}\end{array}$ & $\begin{array}{c}F L \\
/ \mathrm{mL}\end{array}$ & $\mu$ \\
\hline non-additive & 3.5 & 2.8 & 0.7 & 0.2555 & 13.3 & 0.0875 \\
$0.1 \%$ ATS-4 & 5.5 & 2.0 & 3.6 & 1.7885 & 15.0 & 0.0875 \\
$0.5 \%$ ATS-4 & 5.0 & 2.2 & 2.9 & 1.3007 & 125.0 & 0.5774 \\
$1.0 \%$ Modified starch & 6.0 & 4.0 & 2.0 & 0.5110 & 7.5 & 0.0699 \\
$1.0 \%$ Modified starch+0.1\%ATS-4 & 7.1 & 3.4 & 3.8 & 1.1122 & 6.8 & 0.0963 \\
$0.04 \%$ PAM & 8.0 & 4.2 & 3.9 & 0.9247 & 12.0 & 0.0699 \\
$0.04 \%$ PAM+0.1\%ATS-4 & 7.5 & 3.2 & 4.4 & 1.3733 & 20.0 & 0.0437 \\
\hline
\end{tabular}


Table 3 Effect of $0.5 \%$ ATS- 4 on particle size distribution of bentonite

\begin{tabular}{lcc}
\hline \multicolumn{1}{c}{ Additives } & Mean $/ \mu \mathrm{m}$ & Median $/ \mu \mathrm{m}$ \\
\hline Virgin bentonite & 33.26 & 26.65 \\
Hydrated bentonite & 11.06 & 7.64 \\
Virgin bentonite $+0.5 \%$ ATS-4 & 45.72 & 38.30 \\
Hydrated bentonite $+0.5 \%$ ATS-4 & 44.59 & 39.73 \\
\hline
\end{tabular}


Table 4 The main crystal data

\begin{tabular}{ll}
\hline Item & Data \\
\hline Formula sum & $\mathrm{C}_{4} \mathrm{H}_{12} \mathrm{CaO}_{10}$ \\
Crystal system & orthorhombic \\
Space-group & $\mathrm{P} 212121(19)$ \\
Cell parameters & $\mathrm{a}=9.631(2) \AA \mathrm{b}=10.573(3) \AA \mathrm{c}=9.215(2) \AA$ \\
Cell ratio & $\mathrm{a} / \mathrm{b}=0.9109 \mathrm{~b} / \mathrm{c}=1.1474 \mathrm{c} / \mathrm{a}=0.9568$ \\
Cell volume & $938.35(39) \AA^{3}$ \\
$\mathrm{Z}$ & 4 \\
Pearson code & oP108 \\
\hline
\end{tabular}




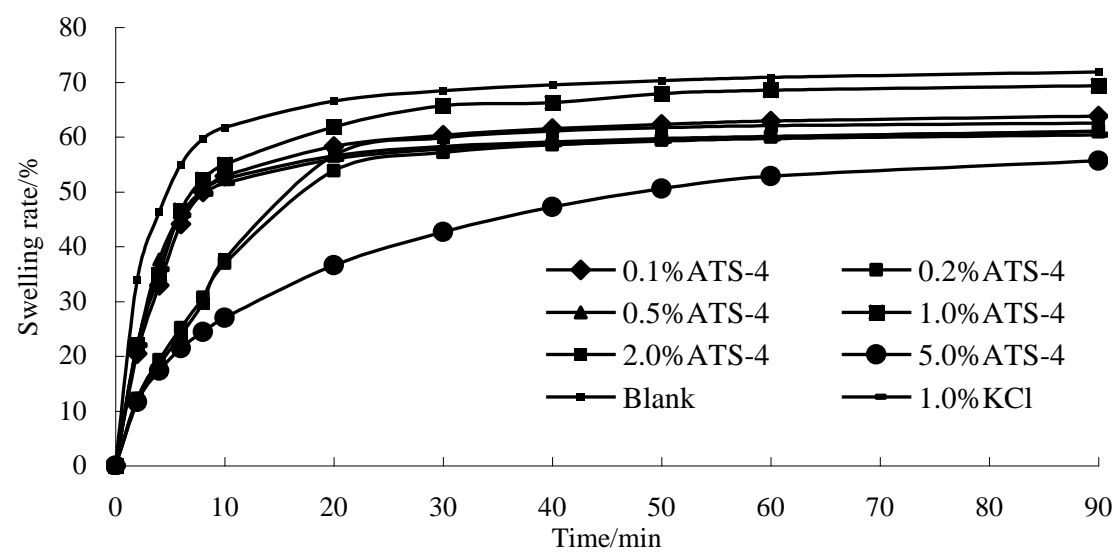

Fig. 1 The effect of inhibitor concentration on the clay-swelling rate 


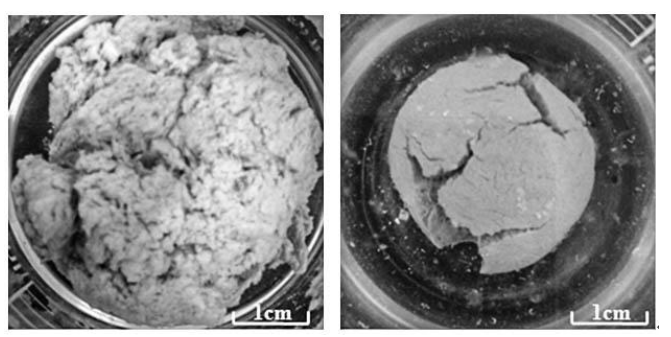

Fig. 2 The status of mud balls immersed in water (left) and 0.5\% ATS-4 solution (right) for $72 \mathrm{~h}$ 


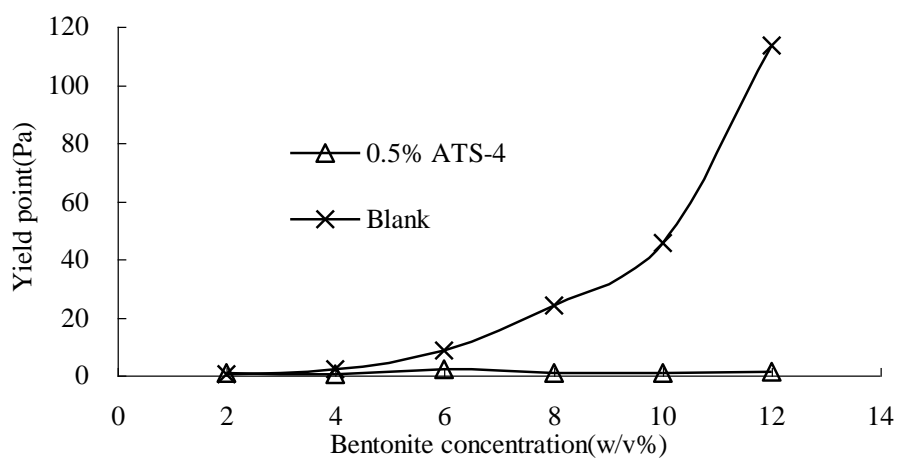

Fig. 3 The effect of yield point of different shale inhibitors with the base fluid 


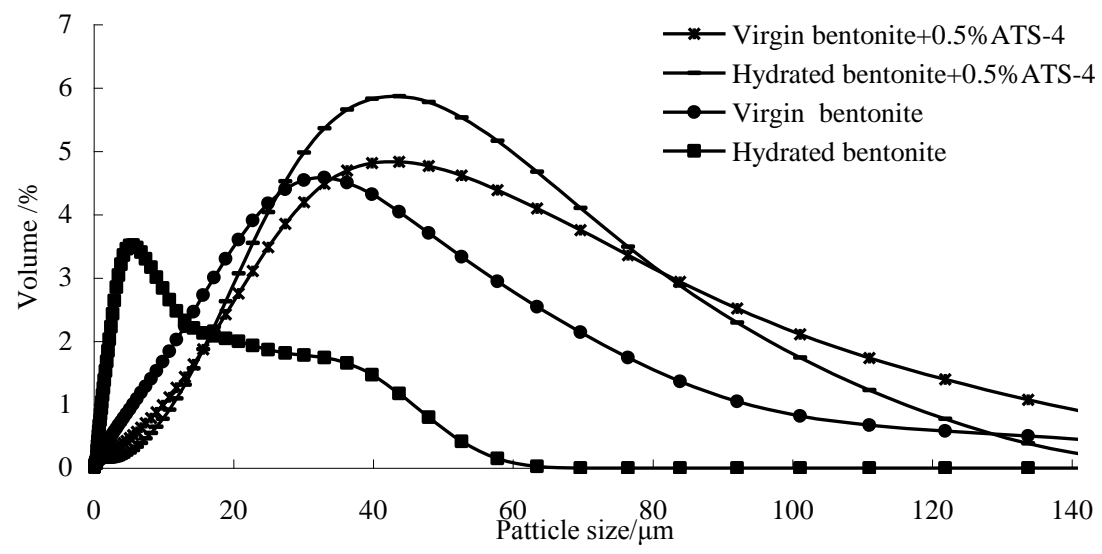

Fig. 4 Effect of $0.5 \%$ ATS-4 on particle size distribution of bentonite 


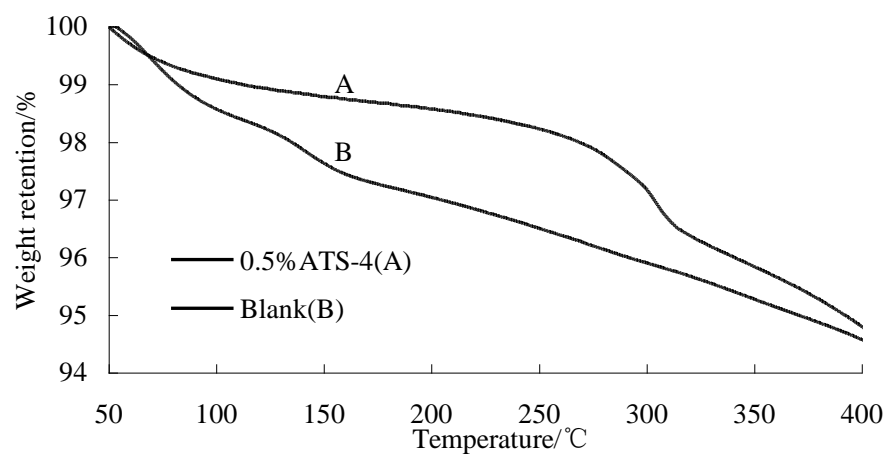

Fig. 5 TGA of water immersed bentonite and 0.5\% ATS-4 solution immersed bentonite 

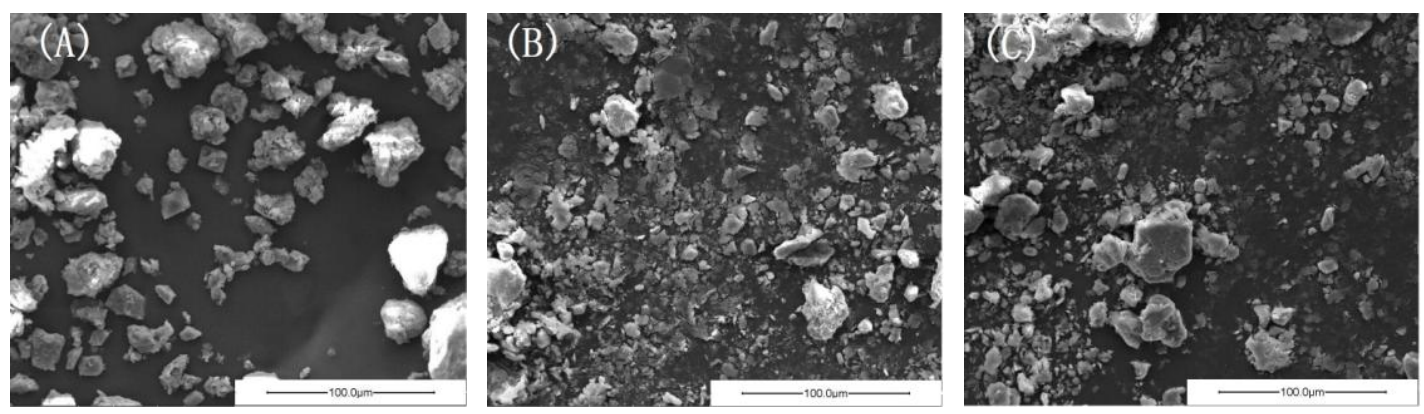

Fig. 6 SEM of bentonite treated with ATS-4 solution (A), bentonite treated with water(B) and virgin bentonite (C) 


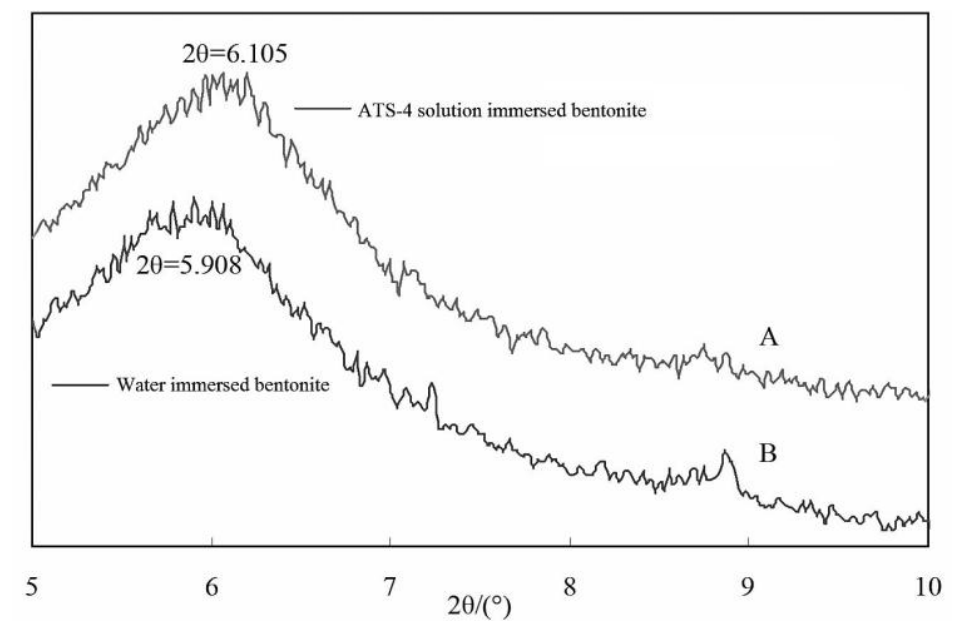

Fig. 7 XRD patterns of water immersed bentonite and $0.5 \%$ ATS-4 solution immersed bentonite 

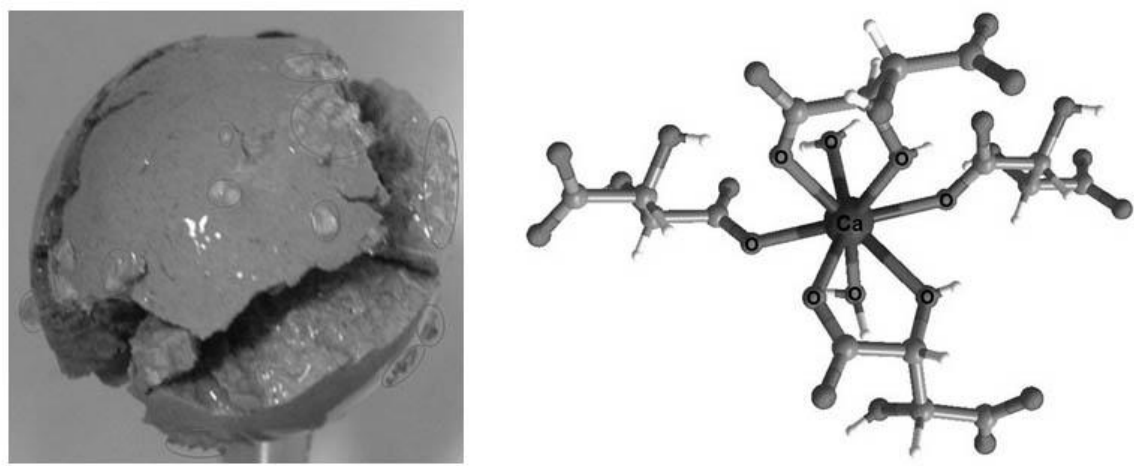

Fig. 8 The analysis for crystal on the surface of mud ball (left) and the structure of the crystal (right) 


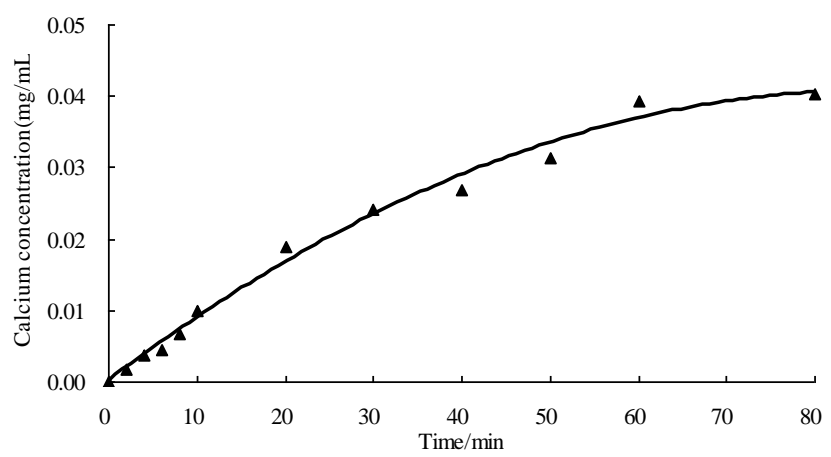

Fig. 9 The change of calcium concentration in $0.5 \%$ ATA-4 solution with time 